\title{
Pengaruh Perkembangan Industri Skala Sedang Dan Besar Yang Teraglomerasi Terhadap Permukiman Di Mojosongo-Teras, KABUPATEN BOYOLALI
}

\author{
Riky Dony Ardian, Ana Hardiana, Rufia Andisetyana Putri \\ Program Studi Perencanaan Wilayah dan Kota, \\ Jurusan Arsitektur, Fakultas Teknik, \\ Universitas Sebelas Maret, Surakarta \\ Email: rikydony92@gmail.com
}

\begin{abstract}
The development of medium and large scale industries are agglomerated in MojosongoTeras started in 2004, the development of the industry led to the pull of labor migration as a form of labor compliance, while also developing new economic activity. With the increasing population and the development of new economic activities, the settlement that have a role as a container that helped develop. The development of settlements in the area affected by industrial agglomeration characterized by an increasing number of buildings, increase the intensity of land use residential, residential facilities and service improvement. The problem in this research to know how to influence the development of medium and large scale industries are agglomerated against settlements in Mojosongo-Teras, Boyolali. The purpose of this study was to determine the effect brought about by the development of medium and large scale industries are agglomerated to the surrounding settlemets. The analytical method used in the method of scoring each sub variables of industrial and residential development, while also using the matrix method to determine the magnitude of the effect of the influence industrial development of the settlement. The result obtained are the development of medium and large scale industries are agglomerated in Mojosongo-Teras effect on the development of the settlement. High-level influence can be interpreted that the development of settlements in the area affected Mojosongo-Teras industrial agglomeration is strongly influenced by the conditions and level of industrial development in the region.
\end{abstract}

Keywords: Agglomeration, Industrial Development, Settlement

\section{PENDAHULUAN}

Sektor industri mempunyai peran penting dalam pertumbuhan ekonomi dan pembangunan ekonomi wilayah. Berkembangnya sektor industri menyebabkan terjadinya peningkatan kegiatan dan jumlah penduduk.

Peningkatan jumlah penduduk terjadi karena perkembangan industri membutuhkan tenaga kerja dengan jumlah dan kualifikasi tertentu yang tidak semuanya bisa disediakan oleh angkatan kerja didekat lokasi industri, maka terjadi migrasi tenaga kerja sebagai bentuk pemenuhan tenaga kerja industri. Terlebih bagi industri skala sedang dan besar yang membutuhkan tenaga kerja relatif banyak dengan kualifikasi dan kemampuan tertentu, memungkinkan adanya pemenuhan tenaga kerja dari luar daerah dengan jumlah relatif besar. Adanya migrasi masuk tersebut menuntut adanya permukiman baru beserta sarana prasarana pendukung sebagai wadah bermukim para migran tenaga kerja tersebut.

Peningkatan jumlah migrasi tenaga kerja dan peningkatan kegiatan masyarakat pada daerah industri cenderung terjadi lebih besar pada industri sedang dan besar, karena industri tersebut memiliki masukan dan luaran yang besar pula. Pengaruh fisik keruangan yang ditimbulkan oleh industri skala sedang dan besar akan membesar jika industri-industri tersebut teraglomerasi. Aglomerasi industri adalah sekumpulan industri yang terkumpul pada suatu tempat dengan pertimbangan penghematan yang diperoleh akibat lokasi yang berdekatan (Soepono, 2002).

Kegiatan industri berkembang cukup pesat di Kabupaten Boyolali, salah satu wilayah yang perkembangan industrinya pesat adalah kawasan industri MojosongoTeras, perkembangan tersebut di mulai sejak tahun 2004. Keberadaan industri saat ini di dominasi industri skala sedang-besar 
yang mayoritas merupakan industri tekstil. Jarak antara industri di kawasan ini berdekatan dan termasuk dalam kategori industri yang teraglomerasi.

Adanya perkembangan industri yang teraglomerasi di wilayah Mojosongo-Teras menyebabkan permukiman di sekitarnya berkembang, terlihat bahwa terdapat perubahan pada permukiman berupa perubahan fisik seperti penggunaan lahan untuk permukiman yang meningkat hingga dan fasilitas-fasilitas pendukung permukiman yang juga meningkat, perkembangan permukiman ini terjadi seiring dengan adanya perkembangan industri. Industri di wilayah MojosongoTeras mempunyai potensi untuk terus berkembang, sedangkan perkembangan industri dapat semakin mempengaruhi kondisi dan perkembangan permukiman di sekitarnya. Tujuan studi ini adalah mengetahui pengaruh perkembangan industri skala sedang dan besar yang teraglomerasi terhadap perkembangan permukiman di Mojosongo-Teras.

\section{METODE}

\subsection{Ruang Lingkup}

Wilayah Penelitian mencakup wilayah seluas $24,47 \mathrm{Km}^{2}$, yang mencakup beberapa desa di Kecamatan Mojosongo dan Kecamatan Teras yang kemudian disebut dengan wilayah terpengaruh aglomerasi industri Mojosongo-Teras, Kabupaten Boyolali.

Sedangkan ruang laingkup materinya mencakup perkembangan industri skala sedng dan besar serta perkembangan permukiman yang ditinjau dari aspek fisik.

Dalam penelitian ini ruang lingkup waktu di mulai dari perkembangan industri saat mengalami peningkatan pesat yang ditandai dibangunnya industriindustri baru pada lokasi penelitian, yaitu pada tahun 2004. Jadi ruang lingkup penelitian dirumuskan adalah tahun 2004 dan 2013.

\subsection{Metode Analisis}

Penelitian ini akan melakukan beberapa tahapan analisis untuk dapat mencapai tujuan dan sasaran penelitian, yaitu mengetahui pengaruh perkembangan indsutri skala menengah dan besar yang teraglomerasi terhadap permukiman di Mojosongo-Teras, Kabupaten Boyolali. Dalam setiap tahapan analisis akan digunakan beberapa teknik analisis untuk mempermudah proses analisisnya. Tahapan beserta teknik analisis yang digunakan dijabarkan sebagai berikut:

a. Identifikasi Perkembangan Industri Skala Sedang dan Besar yang Teraglomerasi.

Identifikasi ini menggunakan teknik analisis skoring, yaitu dengan memberi skor pada setiap subvariabel perkembangan industri berdasarkan tingkat perubahan dalam indikator. Kemudian jumlah skor seluruh sub-variabel diklasifikasikan menjadi perubahan tinggi (>7-9), perubahan sedang $(>5-7)$, dan perubahan rendah (3-5). Selengkapnya dapat di lihat pada Lampiran 1.

b. Identifikasi Perkembangan Permukiman pada Wilayah Terpengaruh Aglomerasi Industri Identifikasi ini menggunakan teknik analisis skoring, yaitu dengan memberi skor pada setiap subvariabel perkembangan permukiman berdasarkan tingkat perubahan dalam indikator.

c. Analisis Pengaruh Perkembangan Industri Skala Sedang dan Besar Yang Teraglomerasi Terhadap Perkembangan Permukiman

Analisis ini menggunakan teknik analisis matriks dan skoring. Matriks pengaruh perkembangan industri terhadap perkembangan permukiman menunjukkan besaran pengaruh adanya perkembangan industri terhadap setiap sub-variabel permukiman yang terdiri dari pengaruh tinggi, pengaruh sedang, dan pengaruh rendah, selengkapnya dapat dilihat pada Lampiran 2 . Matriks yang digunakan untuk mengetahui pengaruh perkembangan industri terhadap setiap sub-variabel perkembangan permukiman 
mempunyai bentuk dan tipologi yang sama. Setelah diketahui besaran pengaruh perkembangan industri terhadap setiap sub-variabel perkembangan permukiman maka perlu dilakukan skoring untuk mengetahui pengaruh perkembangan industri skala sedang dan besar yang teraglomerasi terhadap perkembangan permukiman secara menyeluruh dan diidentifikasi sesuai dalam tabel klasifikasi pengaruh yang terdiri dari pengaruh tinggi ( $>7-9$ ), pengaruh sedang (>5-7), dan pengaruh rendah (3-5), selengkapnya dapat di lihat pada Lampiran 3.

\section{HASIL DAN PEMBAHASAN}

3.1 Identifikasi Perkembangan Industri Skala Sedang dan Besar Yang Teraglomerasi di Mojosongo-Teras

Identifikasi perkembangan industri skala sedang dan besar yang teraglomerasi bertujuan untuk mengetahui karakter perkembangan industri tersebut dalam kurun waktu tahun 2004-2013. Identifikasi ini mencakup identifikasi pertambahan jumlah industri, pertambahan luas lahan industri, serta pertambahan tenaga kerja. Teknik analisis yang digunakan adalah teknik skoring, yaitu dengan memberi skor ke setiap sub variabel sesuai dengan tingkat perubahan indikatornya.

a. Identifikasi Pertambahan Jumlah Industri

Identifikasi ini dilakukan berdasarkan data jumlah dan perubahan industri skala sedang dan besar yang teraglomerasi di Kawasan MojosongoTeras. Selama kurun waktu tahun 2004 - 2013 terdapat Perubahan jumlah industri sedang dan industri besar, dengan jumlah pertambahan 10 industri baru atau terjadi perubahan $62,5 \%$, dengan persentase tersebut maka pertambahan jumlah industri masuk dalam klasifikasi perubahan tinggi dengan skor 3 .

b. Identifikasi Pertambahan Luas Lahan Industri

Identifikasi ini dilakukan berdasarkan data penggunaan lahan industri skala sedang dan besar yang teraglomerasi di Mojosongo-Teras. Selama kurun waktu tahun 2004 - 2013 terdapat perubahan penggunaan lahan untuk industri sebesar 34,09 hektar atau terjadi Perubahan sebesar 57,03\%, dengan persentase tersebut maka pertambahan luas lahan industri termasuk dalam kategori perubahan tinggi dan mempunyai skor 3 .

c. Identifikasi Pertambahan Tenaga Kerja

Identifikasi ini dilakukan berdasarkan data pertambahan jumlah tenaga kerja industri skala sedang dan besar yang teraglomerasi di Mojosongo-Teras. Dalam kurun waktu tahun 2004 - 2013 terdapat pertambahan tenaga kerja sebanyak 7.540 jiwa atau terjadi perubahan sebesar $111,12 \%$, dengan persentase tersebut maka pertambahan tenaga kerja termasuk dalam kategori perubahan sedang dan memiliki skor 3 .

d. Jumlah Skor Identifikasi Perkembangan Industri Skala Sedang dan Besar yang Teraglomerasi di Mojosongo-Teras

Jumlah skor dari ketiga identifikasi terkait perkembangan industri skala sedang dan besar yang teraglomerasi adalah 9, dan termasuk dalam klasifikasi perubahan tinggi.

\subsection{Identifikasi Perkembangan Permukiman Wilayah Terpengaruh Aglomerasi Industri Mojosongo- Teras}

Identifikasi perkembangan permukiman pada wilayah terpengaruh aglomerasi industri bertujuan untuk mengetahui perkembangan fisik permukiman pada wilayah terpengaruh aglomerasi industri, identifikasi ini meliputi beberapa identifikasi sebagai berikut.

a. Identifikasi Peningkatan Jumlah Bangunan Permukiman

Identifikasi ini dilakukan berdasarkan data Peningkatan jumlah bangunan permukiman di wilayah terpengaruh industri Mojosongo-Teras. Dalam kurun waktu tahun 2004 - 2013 terjadi 
pertambahan jumlah bangunan permukiman sebesar 2512 unit atau terjadi perubahan sebesar $33,45 \%$, dengan persentase tersebut maka perubahan jumlah bangunan permukiman masuk dalam kategori perubahan sedang dengan skor 2

b. Identifikasi Peningkatan Intensitas Pemanfaatan Lahan Permukiman Identifikasi ini dilakukan berdasarkan data perubahan intensitas pemanfaatan lahan permukiman di wilayah terpengaruh industri MojosongoTeras. Selama kurun waktu tahun 2004 - 2013 terjadi perubahan intensitas pemanfaatan lahan sebesar 6\%, dan masuk dalam kategori perubahan tinggi dengan skor 3.

c. Identifikasi Peningkatan Pelayanan Fasilitas Permukiman Identifikasi peningkatan pelayanan fasilitas permukiman berpedoman pada standar pelayanan fasilitas permukiman dalam SNI 03-1733-2004 tentang tata cara perencanaan lingkungan perumahan di perkotaan. Hasil identifikasi penigkatan pelayanan fasilitas permukiman di wilayah terpengaruh aglomerasi industri Mojosongo-Teras dijelaskan sebagai berikut.

1) Identifikasi Peningkatan Pelayanan Fasilitas Pendidikan Identifikasi ini dilakukan berdasarkan data jumlah dan rasio pelayanan fasilitas pendidikan di wilayah terpengaruh industri Mojosongo-Teras. Pada tahun 2004 terdapat 60 unit fasilitas pendidikan, dan meningkat 1 unit menjadi 61 unit pada tahun 2013, sedangkan rasio pelayanan fasilitas pendidikan pada tahun 2004 adalah 0,001672 sedangkan pada tahun 2013 sebesar 0,001578. Dapat diidentifikasi bahwa jumlah fasilitas pendidikan meningkat, namun rasio pelayanan menurun dan juga di bawah rasio standar pelayanan sebesar 0,001842. Perubahan pelayanan fasilitas pendidikan termasuk dalam klasifikasi perubahan rendah, dan mempunyai skor 0,25

2) Identifikasi Peningkatan Pelayanan Fasilitas Kesehatan Identifikasi ini dilakukan berdasarkan data jumlah dan rasio pelayanan fasilitas kesehatan di wilayah terpengaruh industri Mojosongo-Teras. Pada tahun 2004 jumlah fasilitas kesehatan sebanyak 3 unit dan meingkat menjadi 6 unit di tahun 2014, sedangkan rasio pelayanan fasilitas kesehatan pada tahun 2004 adalah 0,000084, dan pada tahun 2013 sebesar 0,000155. Dapat diidentifikasi bahwa jumlah dan rasio pelayanan fasilitas kesehatan meningkat dan berada di atas rasio standar pelayanan sebesar 0,000080. Peningkatan pelayanan fasilitas kesehatan termasuk dalam klasifikasi perubahan tinggi, dan mempunyai skor 0,75 .

3) Identifikasi Peningkatan Pelayanan Fasilitas Peribadatan

Identifikasi ini dilakukan berdasarkan data jumlah dan rasio pelayanan fasilitas peribadatan di wilayah terpengaruh industri Mojosongo-Teras. Pada tahun 2004 terdapat 163 unit fasilitas peribadatan dan meningkat menjadi 178 unit pada tahun 2013, sedangkan rasio pelayanan fasilitas peribadatan pada tahun 2004 adalah 0,004989, dan pada tahun 2013 sebesar 0,005101. Dapat diidentifikasi bahwa jumlah dan rasio pelayanan meningkat namun masih berada di bawah 
rasio standar pelayanan sebesar 0,005400. Peningkatan pelayanan fasilitas peribadatan termasuk dalam klasifikasi perubahan sedang, dan mempunyai skor 0,5 .

4) Identifikasi Peningkatan Pelayanan Fasilitas Perdagangan dan Niaga Identifikasi ini dilakukan berdasarkan data jumlah dan rasio pelayanan fasilitas perdagangan dan niaga di wilayah terpengaruh industri Mojosongo-Teras. Pada tahun 2004 terdapat 525 unit fasilitas perdagangan dan niaga, meningkat drastis menjadi 822 unit pada tahun 2013, sedangkan rasio pelayanan fasilitas perdagangan dan niaga pada tahun 2004 adalah 0,014633, dan pada tahun 2013 sebesar 0,021271. Dapat diidentifikasi bahwa jumlah dan rasio pelayanan meningkat dan berada di atas rasio standar pelayanan sebesar 0,008200. Peningkatan pelayanan fasilitas perdagangan dan niaga termasuk dalam klasifikasi perubahan tinggi, dan mempunyai skor 0,75 .

5) Jumlah Skor Identifikasi Perkembangan Permukiman Wilayah Terpengaruh aglomerasi Industri Mojosongo-Teras

Jumlah skor dari ketiga identifikasi terkait perkembangan industri skala sedang dan besar yang teraglomerasi adalah 9, dan termasuk dalam klasifikasi perubahan sedang.

\subsection{Analisis Pengaruh Perkembangan Industri Skala Sedang dan Besar yang Teraglomerasi di Mojosongo-Teras}

Untuk melakukan analisis pengaruh perkembangan industri skala sedang dan besar yang teraglomerasi terhadap perkembangan permukiman di
Mojosongo-Teras dilakukan dengan matriks pengaruh dan skoring. Matriks ini menunjukkan pengaruh yang ditimbulkan perkembangan industri yang teraglomerasi di Mojosongo-Teras dengan setiap sub-variabel perkembangan permukiman, dan diuraikan sebagai berikut.

a. Analisis Pengaruh Perkembangan Industri Skala Sedang dan Besar yang Teraglomerasi terhadap Peningkatan Jumlah Bangunan Permukiman di Mojosongo-Teras

Matriks pengaruh perkembangan industri skala sedang dan besar yang teraglomerasi terhadap peningkatan jumlah bangunan permukiman di Mojosongo-Teras menunjukkan bahwa kondisi perkembangan industri yang mengalami perubahan sedang berpengaruh sedang terhadap peningkatan jumlah bangunan, sedangkan kondisi peningkatan jumlah bangunan berada pada kategori perubahan sedang.

b. Analisis Pengaruh Perkembangan Industri Skala Sedang dan Besar yang Teraglomerasi terhadap Peningkatan Intensitas Pemanfaatan Lahan Permukiman di Mojosongo-Teras.

Matriks pengaruh perkembangan industri skala sedang dan besar yang teraglomerasi terhadap peningkatan intensitas penggunaan lahan permukiman di Mojosongo-Teras menunjukkan bahwa kondisi perkembangan industri yang mengalami perubahan sedang berpengaruh tinggi terhadap peningkatan intensitas pemanfaatan lahan permukiman, sedangkan kondisi perubahan penggunaan lahan berada pada kategori perubahan tinggi.

c. Analisis Pengaruh Perkembangan Industri Skala Sedang dan Besar yang Teraglomerasi terhadap Peningkatan Jumlah Bangunan Permukiman di Mojosongo-Teras.

Matriks pengaruh perkembangan industri skala sedang dan besar yang teraglomerasi terhadap peningkatan pelayanan fasilitas permukiman di Mojosongo-Teras menunjukkan 
bahwa kondisi perkembangan industri yang mengalami perubahan sedang, berpengaruh tinggi terhadap peningkatan pelayanan fasilitas permukiman, sedangkan kondisi peningkatan pelayanan fasilitas permukiman berada pada kategori perubahan tinggi.

3.4 Analisis Pengaruh Perkembangan Industri Skala Sedang dan Besar yang Teraglomerasi di MojosongoTeras terhadap Perkembangan Permukiman

Untuk melakukan analisis ini perlu dilakukan skoring dari tingkat pengaruh perkembangan industri terhadap setiap sub variabel perkembangan permukiman yang terdiri dari peningkatan jumlah bangunan permukiman, perubahan penggunaann lahan permukiman, peningkatan pelayanan fasilitas pendidikan, peningkatan pelayanan fasilitas kesehatan, peningkatan pelayanan fasilitas peribadatan, serta peningkatan pelayanan fasilitas perdagangan dan niaga. Jumlah skor yang didapatkan dari pertambahan skor seluruh sub-variabel perkembangan permukiman adalah 7 dan termasuk dalam kategori tingkat pengaruh sedang, hal ini menunjukkan pengaruh perkembangan industri skala sedang dan besar yang teraglomerasi di Mojosongo-Teras berpengaruh tinggi terhadap perkembangan permukiman di sekitarnya.

\section{KESIMPULAN}

Perkembangan industri skala sedang dan besar yang teraglomerasi di Mojosongo-Teras berpengaruh tinggi terhadap perkembangan permukiman di sekitarnya. Tingkat pengaruh tinggi dapat diartikan bahwa perkembangan permukiman di wilayah terpengaruh aglomerasi industri Mojosongo-Teras sangat dipengaruhi oleh kondisi dan tingkat perkembangan industri di wilayah tersebut.

Perkembangan Industri dan Permukiman di wilayah terpengaruh aglomerasi industri Mojosongo-Teras lebih pesat dibandingkan dengan perkembangan yang terjadi di
Kabupaten Boyolali. Hal ini menunjukkan aglomerasi industri Mojosongo-Teras mempunyai pengaruh lebih tinggi dibandingkan pada perkembangan permukiman, dibandingkan dengan industri di wilayah regional Kabupaten Boyolali.

\section{REFERENSI}

SNI 03-1733-2004 tentang Tata cara perencanaan lingkungan perumahan di perkotaan

Soepono, Prasetyo. 2002. Lokasi Perusahaan dan Implikasinya Bagi Kebijakan. Yogyakarta: Pidato Pengukuhan Guru Besar FE UGM 


\section{LAMPIRAN}

Lampiran 1. Klasifikasi Skor Identifikasi

Perkembangan Industri

\begin{tabular}{|c|c|}
\hline Skor & Klasifikasi \\
\hline$>7-9$ & Perubahan Tinggi \\
\hline$>5-7$ & Perubahan Sedang \\
\hline $3-5$ & Perubahan Rendah \\
\hline
\end{tabular}

Sumber: Identifikasi Peneliti, 2014

Lampiran 2. Matriks Pengaruh

Perkembangan Industri terhadap

Sub-Sub Variabel

Perkembangan Permukiman

\begin{tabular}{|c|c|c|c|}
\hline Sub Variabel Perkembangan \\
Permukiman (....) \\
$\begin{array}{c}\text { Perkembangan } \\
\text { Industri }\end{array}$ & $\begin{array}{c}\text { Perubahan } \\
\text { Tinggi }\end{array}$ & $\begin{array}{c}\text { Perubahan } \\
\text { Sedang }\end{array}$ & $\begin{array}{c}\text { Perubahan } \\
\text { Rendah }\end{array}$ \\
\hline Perubahan Tinggi & $\begin{array}{c}\text { Pengaruh } \\
\text { Sedang }\end{array}$ & $\begin{array}{c}\text { Pengaruh } \\
\text { Rendah }\end{array}$ & $\begin{array}{c}\text { Pengaruh } \\
\text { Rendah }\end{array}$ \\
\hline Perubahan Sedang & $\begin{array}{c}\text { Pengaruh } \\
\text { Tinggi }\end{array}$ & $\begin{array}{c}\text { Pengaruh } \\
\text { Sedang }\end{array}$ & $\begin{array}{c}\text { Pengaruh } \\
\text { Rendah }\end{array}$ \\
\hline Perubahan Rendah & Pengaruh & Pengaruh \\
Tinggi & $\begin{array}{c}\text { Pengaruh } \\
\text { Sedang }\end{array}$ \\
\hline
\end{tabular}

Sumber: Identifikasi Peneliti, 2014

Lampiran 3. Klasifikasi Pengaruh

\begin{tabular}{|c|c|}
\hline Interval Skor & Klasifikasi Pengaruh \\
\hline$>7-9$ & Perngaruh Tinggi \\
\hline$>5-7$ & Pengaruh Sedang \\
\hline $3-5$ & Pengaruh Rendah \\
\hline
\end{tabular}

Sumber: Identifikasi Peneliti, 2015 